\title{
Detecção do vírus Epstein-Barr (EBV) em adenocarcinomas gástricos procedentes dos estados do Ceará e de São Paulo
}

\author{
Epstein-Barr virus (EBV) detection in gastric carcinomas from Ceará and São Paulo states, in Brazil \\ Marcos Antonio Pereira de Lima'; Márcia Valéria Pitombeira Ferreira²; Marcos Aurélio Pessoa Barros ${ }^{3}$; \\ Maria Inês de Moura Campos Pardini ${ }^{4}$; Adriana Camargo Ferrasij; ${ }^{5}$ Silvia Helena Barem Rabenhorst ${ }^{6}$
}

Unitermos
EBV
Adenocarcinoma gástrico
Hibridização in situ

\section{resumo}

Introdução: $O$ vírus Epstein-Barr (EBV) está associado a cerca de $10 \%$ dos adenocarcinomas gástricos, representando mais de 50 mil casos por ano no mundo. Apesar dos estudos realizados em várias partes do mundo, alguns aspectos clinicopatológicos permanecem controversos. Objetivos: $O$ presente estudo teve como objetivo analisar as características clinicopatológicas de casos de adenocarcinomas gástricos procedentes dos estados de São Paulo e Ceará, correlacionando-os com a detecção de EBV. Materiais e métodos: Foram obtidos 192 casos de adenocarcinomas gástricos de hospitais dos estados de São Paulo e do Ceará, dos quais 160 foram submetidos à técnica de RNA-hibridização in situ para detecção de EBV. Resultados: Dos 160 casos, 11 (6,9\%) foram EBV-positivo, exibindo intensa marcação nuclear em células tumorais. Destes, dois casos também apresentaram linfócitos infiltrados marcados. Não encontramos marcação em tecido normal ou pré-neoplásico. São Paulo e Ceará apresentaram as frequências $3 / 60(5 \%)$ e 8/100 (8\%), respectivamente, e maior relação do EBV com indivíduos do sexo masculino, de idade avançada, com tumores do tipo intestinal, de estadiamento elevado e grau pouco a moderadamente diferenciado. Os casos do Ceará exibiram aumento relativo de tumores EBV $(+)$ localizados na cárdia, enquanto os casos de São Paulo demonstraram aumento naqueles localizados no corpo gástrico. Conclusão: A frequência de tumores $\mathrm{EBV}(+)$ do presente estudo situa-se nos valores descritos na literatura mundial. Entre os achados, um deles não encontra paralelo na literatura mundial e refere-se ao elevado percentual de tumores EBV(+) no corpo gástrico observado nos casos de São Paulo.

\section{abstract}

Introduction: The Epstein-Barr virus (EBV) has been associated with approximately $10 \%$ of gastric adenocarcinomas, which represents more than 50,000 cases/year worldwide. Despite the studies undertaken in several countries, some clinical-pathological aspects remain contentious. Objective: The objective of this study was to analyze clinical-pathological features of gastric adenocarcinomas from two Brazilian states, São Paulo and Ceará, by correlating them with EBV detection. Materials and methods: One hundred ninety-two gastric adenocarcinoma cases were selected from hospitals in São Paulo and Ceará, of which 160 were submitted to RNA in situ hybridization for EBV detection. Results: Eleven (6.9\%) out of 160 cases were EBV-positive with intense nuclear staining in tumor cells. Among these, two cases also showed stained infiltrating lymphocytes. There was no staining in normal or preneoplastic tissue. São Paulo and Ceará yielded the respective results: $3 / 60$ (5\%) and 8/100 (8\%). In both states, EBV was more prevalent among elder male patients with little to moderately differentiated intestinal tumors in advanced stage. Ceará cases substantiated a relative increase in EBV(+) tumors located in the cardia, whereas São Paulo cases presented an increase in the gastric corpus. Conclusion: The frequency of $E B V(+)$ tumors is similarly described in the literature. Among our findings, the elevated percentage of EBV(+) tumors in the gastric corpus, which was observed in São Paulo cases, is unprecedented in the literature.

\section{key words}

$E B V$

Gastric carcinoma

In situ hybridization

\footnotetext{
1. Mestre em Microbiologia Médica; professor assistente da Faculdade de Medicina da Universidade Federal do Ceará (UFC), Campus Cariri.

2. Doutora em Bioquímica; mestra em Patologia; professora adjunta da Faculdade de Medicina da UFC, Campus Porangabuçu.

3. Mestre em Cirurgia; cirurgião do Hospital Universitário Walter Cantídeo (HUWC) da UFC.

4. Pós-doutora em Biologia Molecular; doutora e mestra em Ciências Biológicas (Cenética); professora adjunta da Faculdade de Medicina da Universidade Estadual Paulista (UNESP), Campus Botucatu.

5. Doutora e mestra em Ciências Biológicas; professora titular da UNESP.

6. Pós-doutora em Cenética Molecular; doutora e mestra em Ciências Biológicas (Cenética); professora associada da Faculdade de Medicina da UFC, Campus Porangabuçu.
} 


\section{Introdução}

O vírus Epstein-Barr (EBV) é um membro da subfamília gama-herpesvírus com ampla distribuição mundial. Estima-se que mais de $90 \%$ da população mundial adulta esteja infectada por esse vírus e transmitindo-o intermitentemente por meio da saliva ${ }^{(19)}$. Na maioria dos indivíduos, o EBV promove uma infecção assintomática, persistindo no organismo hospedeiro, principalmente em linfócitos $B$. Contudo, também está associado a várias desordens linfoides, como mononucleose infecciosa, linfoma de Burkitt, doença de Hodgkin e doença linfoproliferativa pós-transplante, bem como desordens de linhagem epitelial, como leucoplasia pilosa, carcinoma de nasofaringe e adenocarcinoma gástrico ${ }^{(26)}$. Neste último, o EBV tem sido demonstrado em aproximadamente $10 \%$ dos casos, utilizando a técnica de hibridização in situ para o transcrito viral EBER1, variando de 1,3\% a 23,6\%, dependendo da região mundial estudada ${ }^{(9,29)}$.

Diversos fatores estão relacionados com o desenvolvimento de câncer gástrico, como elevado consumo de sal, alimentos em conserva contendo compostos nitrogenados, baixo consumo de frutas e vegetais, cirurgia gástrica, lesões benignas prévias, tabagismo e infecção por Helicobacter pylori. Alguns autores aventam o envolvimento do fator socioeconômico ${ }^{(2,4,8,37)}$. De fato, tem sido relatado que dois terços dos casos de câncer de estômago ocorrem em países em desenvolvimento ${ }^{(36)}$.

No que se refere aos adenocarcinomas, os quais respondem por $90 \%$ a $95 \%$ dos cânceres de estômago ${ }^{(6,39)}$, desde o início da década de 1990 que o EBV tem sido apontado como fator de risco para o desenvolvimento dessa neoplasia ${ }^{(40)}$. Anualmente, são estimados mais de 50 mil casos de adenocarcinomas gástricos $\mathrm{EBV}(+)$ no mun$\mathrm{do}^{(41)}$. Todavia, são observadas algumas diferenças regionais quanto à frequência de carcinomas $\mathrm{EBV}(+)$. Os países cujos estudos realizados demonstraram frequências mais elevadas são Japão (19,3\%), Alemanha (18\%) e Estados Unidos da América $(12 \% \text { a } 16 \%)^{(14,17,35,40)}$. Dois trabalhos desenvolvidos no Brasil mostraram frequências intermediárias, $8 \% \mathrm{e}$ $11,3 \%{ }^{(21,27)}$; ambos envolveram somente pacientes provenientes do estado de São Paulo. Essas diferenças observadas ao redor do mundo sugerem que a frequência de EBV em carcinomas gástricos possa ser afetada por fatores ambientais e, possivelmente, pela origem étnica. Este último pode ser mais bem ilustrado pelo estudo de Koriyama et al.(21), envolvendo brasileiros descendentes e não descendentes de japoneses, no qual houve diferença na frequência de EBV entre os dois grupos, 4,7\% e 11,2\%, respectivamente.
Embora haja consenso sobre alguns aspectos epidemiológicos e patológicos relacionados com a infecção pelo EBV em carcinomas gástricos, a literatura ainda se mostra controversa em outros pontos, dada à complexidade desse tipo de câncer. Nesse cenário, este estudo teve como objetivo analisar as características clinicopatológicas de casos de carcinoma gástrico correlacionando-o com a detecção de EBV. Os casos são provenientes de dois estados brasileiros com diferentes panoramas: São Paulo, situado na região Sudeste do país, apresentando, de modo geral, melhores condições socioeconômicas e um clima temperado; e o Ceará, situado na região Nordeste, de clima semiárido e com condições socioeconômicas relativamente inferiores. Esses estados também diferem quanto às origens étnicas $\mathrm{e}$ hábitos alimentares.

\section{Materiais e métodos}

\section{Espécimes clínicos}

Foram incluídos 192 casos de adenocarcinomas gástricos coletados durante cirurgia em dois hospitais de São Paulo: Hospital das Clínicas de Botucatu (da Universidade Estadual Paulista [UNESP]) e Hospital Amaral Carvalho, em Jaú; e dois do Ceará: Hospital Universitário Walter Cantídeo (da Universidade Federal do Ceará [UFC]) e Santa Casa de Misericórdia de Fortaleza. Espécimes clínicos representativos fixados em formalina e incluídos em blocos de parafina foram selecionados e submetidos a cortes histológicos de $5 \mu \mathrm{m}$, seguidos de fixação em lâminas silanizadas, para a realização de coloração de hematoxilina e eosina (HE) e técnica de hibridização in situ para deteç̧ão do EBV. Dados clínicos e patológicos foram obtidos por meio de pesquisa de prontuários médicos.

Este estudo foi aprovado previamente pelo Comitê de Ética em Pesquisa da Universidade Federal do Ceará sob o protocolo n. 199/2004, estando de acordo com os preceitos da Resolução 196/1996 de Conselho Nacional de Saúde/MS.

\section{Hibridização in situ para EBV}

O EBV foi detectado pela expressão do RNA EBER1 (do inglês, EBV-encoded small RNA-1). A técnica de hibridização in situ foi aplicada utilizando-se sonda biotinilada de $30 \mathrm{pb}$ complementar ao RNA EBER1, como descrito por Shibata e Weiss ${ }^{(40)}$. De modo sucinto, após desparafinação e reidratação dos cortes fixados, o bloqueio da peroxidase endógena 
foi realizado com solução de água oxigenada a 3\% por 10 minutos, seguida de digestão enzimática com proteinase $\mathrm{K}$ (concentração final de 0,02 $\mu \mathrm{g} / \mu \mathrm{l}$ ) por 13 minutos. Os cortes foram submetidos à solução de pré-hibridização (solução de Denhardt [3,5X]; SSC [4,5X]; EDTA [0,0075 M]; SDS [0,35\%]; $\mathrm{NaH}_{2} \mathrm{PO}_{4}[0,75 \mathrm{M}]$; sulfato de dextrano [10\%]) por 60 minutos a $37^{\circ} \mathrm{C}$. Em seguida, foram incubadas a $37^{\circ} \mathrm{C}$ por 16 horas, com solução de hibridização contendo $0,3 \mathrm{ng} / \mu \mathrm{l}$ de sonda. Após três lavagens com tampão 2 X SSC, o sinal foi amplificado usando-se o anticorpo antibiotina (clone BK, mouse, diluição 1:20; DakoCytomation ${ }^{\circledR}$, Dinamarca) e anticorpo anti-imunoglobulina (policlonal, rabbit, diluição 1:100; DakoCytomation ${ }^{\circledR}$, Dinamarca). A detecção foi realizada com o uso do método da estreptavidina-biotinaperoxidase (DakoCytomation ${ }^{\circledast}$, Califórnia, EUA) e o cromógeno 3,3'-diaminobenzidina (DakoCytomation ${ }^{\circledR}$, Califórnia, EUA). Os cortes foram contracorados com hematoxilina de Harris. Em cada reação, como controle positivo, foi adicionado um caso de carcinoma de nasofaringe sabidamente positivo para EBV, assim como um controle negativo pela omissão da sonda em outro caso. Núcleos com marcação entre marrom e preto foram considerados positivos.

\section{Análise estatística}

A análise foi realizada com uso do programa estatístico EPINFO ${ }^{\circledR}$, versão $6.04 \mathrm{~d}$. Os testes estatísticos aplicados incluíram o qui-quadrado de Mantel-Haenszel e o exato de Fisher. Os resultados foram considerados estatisticamente significativos quando o valor de $p<0,05$.

\section{Resultados}

A Tabela 1 mostra os dados clinicopatológicos e a frequência de EBV, detectados por hibridização in situ, nos casos de São Paulo e do Ceará. Em geral, os casos analisados foram mais frequentes em homens e indivíduos com idade avançada, sobretudo acima de 65 anos, com predomínio de tumores localizados no antro gástrico, do tipo intestinal de Lauren, de estadiamento avançado e pouco a moderadamente diferenciados. Apesar das similaridades na maioria dos parâmetros verificados entre os dois estados, algumas diferenças devem ser apontadas: a) São Paulo apresentou baixo percentual (6\%) de tumores localizados na região gástrica superior, incluindo cárdia e fundo, quando em comparação com o Ceará $(23 \%)(p=0,003) ; b)$ houve predomínio de tumores do tipo intestinal nos casos de São Paulo (75\%), em contraste com o equilíbrio observado entre os tipos intestinal e difuso nos casos procedentes do Ceará $(p=0,019) ; c)$ os casos do Ceará demonstraram elevado número de tumores com estadiamento IV (31\%) $(p=0,047) ; d)$ os casos de São Paulo exibiram percentual mais elevado de tumores bem diferenciados $(p=0,003)$; e) a frequência de EBV foi um pouco mais baixa nos casos oriundos de São Paulo.

Como demonstrado na Tabela 1, 11/160 (6,9\%) casos submetidos à hibridização in situ foram positivos para EBV, exibindo intensa marcação nuclear (Figuras 1A e 1B). Entre os casos positivos, nove apresentaram marcação em quase todas as células tumorais, representando um padrão difuso, e apenas dois casos demonstraram padrão focal. Não obstante, em dois casos com marcação em células tumorais também foi verificada marcação nuclear em linfócitos infiltrados. Não foi observada marcação em células do tecido normal ou pré-neoplásico circundante.

A Tabela 2 apresenta a correlação entre o resultado da hibridização in situ e os dados clinicopatológicos dos casos dos dois estados envolvidos. Sobre o sexo dos pesquisados, apesar de não demonstrarem significância estatística, os resultados, em ambos os estados, revelaram maior associação do EBV com o sexo masculino. Quanto à faixa etária, notouse maior frequência em idades avançadas; não obstante, a média de idade $(59,7)$ dos casos EBV $(+)$ do Ceará mostrouse um pouco inferior em relação aos casos não infectados $(61,3)$, enquanto os casos de São Paulo mostraram situação inversa, média de idade dos casos EBV(+) de 67 e dos casos EBV(-) de 64,4.

A correlação do EBV com o sítio anatômico demonstrou, nos casos do Ceará, um aumento relativo no percentual de tumores $E B V(+)$ localizados na cárdia, porém sem exibir significância estatística. Por outro lado, nos casos de São Paulo, houve um significativo aumento percentual dos casos localizados no corpo gástrico $(p=0,045)$. Quanto à classificação de Lauren, em ambos os estados verificou-se maior associação do EBV com tumores do tipo intestinal, exibindo uma tendência nos casos do Ceará $(p=0,089)$. Para ambos os estados, o EBV mostrou-se mais frequente nos tumores mais agressivos, sobretudo nos de estadiamento IIIB e naqueles pouco a moderadamente diferenciados.

\section{Discussão}

O câncer gástrico é a quarta neoplasia mais frequente no mundo e a segunda causa de morte por câncer ${ }^{(4,36)}$. No Brasil, de acordo com o Instituto Nacional de Câncer 
Comparação de dados clinicopatológicos e detecção de EBV entre os casos de São Paulo $(n=92)$ Tabela 1 e do Ceará $(n=100)$

\begin{tabular}{|c|c|c|c|c|c|c|c|}
\hline & & eará & & São Pau & & & Total \\
\hline & $\mathrm{N}$ & $n(\%)$ & $\mathrm{N}$ & $n(\%)$ & Valor $p$ & $\mathrm{~N}$ & $n(\%)$ \\
\hline $\begin{array}{l}\text { Sexo } \\
\text { Masculino } \\
\text { Feminino }\end{array}$ & 100 & $\begin{array}{l}67(67 \%) \\
33(33 \%)\end{array}$ & 50 & $\begin{array}{l}36(72 \%) \\
14(28 \%)\end{array}$ & 0,535 & 150 & $\begin{array}{c}103(68,7 \%) \\
47(31,3 \%)\end{array}$ \\
\hline $\begin{array}{c}\text { Faixa etária* } \\
15-44 \\
45-54 \\
55-64 \\
\geq 65\end{array}$ & 100 & $\begin{array}{c}9(9 \%) \\
20(20 \%) \\
25(25 \%) \\
46(46 \%)\end{array}$ & 49 & $\begin{array}{l}6(12,2 \%) \\
8(16,3 \%) \\
13(26,5 \%) \\
22(44,9 \%)\end{array}$ & 0,892 & $149 *$ & $\begin{array}{l}15(10,1 \%) \\
28(18,8 \%) \\
38(25,5 \%) \\
68(45,6 \%)\end{array}$ \\
\hline $\begin{array}{l}\text { Sítio anatômico } \\
\text { Cardia } \\
\text { Corpo } \\
\text { Antro }\end{array}$ & 100 & $\begin{array}{l}23(23 \%) \\
23(23 \%) \\
54(54 \%)\end{array}$ & 67 & $\begin{array}{c}4(6 \%) \\
11(16,4 \%) \\
52(77,6 \%)\end{array}$ & 0,003 & 167 & $\begin{array}{c}27(16,2 \%) \\
34(20,3 \%) \\
106(63,5 \%)\end{array}$ \\
\hline $\begin{array}{l}\text { Classificação } \\
\text { de Lauren } \\
\text { Intestinal } \\
\text { Difuso }\end{array}$ & 100 & $\begin{array}{l}59(59 \%) \\
41(41 \%)\end{array}$ & 92 & $\begin{array}{l}69(75 \%) \\
23(25 \%)\end{array}$ & 0,019 & 192 & $\begin{array}{c}128(66,7 \%) \\
64(33,3 \%)\end{array}$ \\
\hline $\begin{array}{l}\text { pTNM } \\
\text { In situ } \\
\text { IA } \\
\text { IB } \\
\text { II } \\
\text { IIIA } \\
\text { IIIB } \\
\text { IV }\end{array}$ & 100 & $\begin{array}{c}0(0 \%) \\
3(3 \%) \\
11(11 \%) \\
19(19 \%) \\
25(25 \%) \\
11(11 \%) \\
31(31 \%)\end{array}$ & 91 & $\begin{array}{c}1(1,1 \%) \\
4(4,4 \%) \\
5(5,5 \%) \\
17(18,7 \%) \\
24(26,4 \%) \\
24(26,4 \%) \\
16(17,6 \%)\end{array}$ & 0,047 & 191 & $\begin{array}{c}1(0,5 \%) \\
7(3,7 \%) \\
16(8,4 \%) \\
36(18,8 \%) \\
49(25,7 \%) \\
35(18,3 \%) \\
47(24,6 \%)\end{array}$ \\
\hline $\begin{array}{l}\text { Diferenciação } \\
\text { Indiferenciado } \\
\text { Pouco } \\
\text { Moderadamente } \\
\text { Bem diferenciado }\end{array}$ & 100 & $\begin{array}{c}1(1 \%) \\
41(41 \%) \\
54(54 \%) \\
4(4 \%)\end{array}$ & 59 & $\begin{array}{c}0(0 \%) \\
23(39 \%) \\
23(39 \%) \\
13(22 \%)\end{array}$ & 0,003 & 159 & $\begin{array}{c}1(0,6 \%) \\
64(40,3 \%) \\
77(48,4 \%) \\
17(10,7 \%)\end{array}$ \\
\hline $\begin{array}{l}\text { Hibridização in situ } \\
\text { EBV(+) } \\
\text { EBV(-) }\end{array}$ & 100 & $\begin{array}{c}8(8 \%) \\
92(92 \%)\end{array}$ & 60 & $\begin{array}{c}3(5 \%) \\
57(95 \%)\end{array}$ & 0,538 & 160 & $\begin{array}{c}11(6,9 \%) \\
149(93,1 \%)\end{array}$ \\
\hline
\end{tabular}

*Média geral de idade =61,5; mediana = 63; mínimo = 23; máximo = 98; média de idade dos casos do Ceará = 61,2; média de idade dos casos de São Paulo $=62,3 ;$ EBV: vírus Epstein-Barr; pTNM: TNM patológico.

$(\mathrm{INCA})^{(4)}$, é o quarto tumor mais notificado entre os homens e o sexto entre as mulheres. Na região Nordeste, o câncer gástrico é o terceiro tipo mais comum entre os homens e o quinto entre as mulheres, enquanto na região Sudeste, assim como o perfil nacional, é o quarto entre os homens e o sexto entre as mulheres. As variações de incidência desse tipo de câncer, observadas entre as regiões do Brasil, podem ser decorrentes da diversidade étnica existente no país, bem como das diferenças de fatores ambientais, hábitos alimentares e condições socioeconômicas. Tem sido relatado que dois terços dos casos de câncer de estômago ocorrem em países em desenvolvimento(4, 36), sugerindo, assim como 
Tabela 2 Correlação entre a hibridização in situ para EBV e os dados clinicopatológicos dos casos do Ceará e de São Paulo

\begin{tabular}{|c|c|c|c|c|c|c|c|c|}
\hline & \multicolumn{3}{|c|}{ Ceará } & \multirow{2}{*}{$\begin{array}{l}\text { Valor } \\
\text { de } p\end{array}$} & \multicolumn{3}{|c|}{ São Paulo } & \multirow{2}{*}{$\begin{array}{l}\text { Valor } \\
\text { de } p\end{array}$} \\
\hline & N & EBV(+) & EBV(-) & & N & EBV(+) & EBV(-) & \\
\hline $\begin{array}{l}\text { Sexo } \\
\text { Masculino } \\
\text { Feminino }\end{array}$ & 100 & $\begin{array}{c}7(87,5 \%) \\
1(12,5 \%)\end{array}$ & $\begin{array}{l}60(65,2 \%) \\
32(34,8 \%)\end{array}$ & 0,200 & 18 & $\begin{array}{c}2(1000 \%) \\
0(0,0 \%)\end{array}$ & $\begin{array}{c}10(62,5 \%) \\
6(37,5 \%)\end{array}$ & 0,302 \\
\hline $\begin{array}{l}\text { Faixa etária* } \\
\begin{array}{l}15-44 \\
45-54 \\
55-64 \\
\geq 65\end{array}\end{array}$ & 100 & $\begin{array}{c}1(12,5 \%) \\
2(25 \%) \\
1(12,5 \%) \\
4(50 \%)\end{array}$ & $\begin{array}{c}8(8,7 \%) \\
18(19,6 \%) \\
24(26,1 \%) \\
42(45,7 \%)\end{array}$ & 0,849 & 17 & $\begin{array}{l}0(0 \%) \\
0(0 \%) \\
0(0 \%) \\
0(0 \%)\end{array}$ & $\begin{array}{c}2(13,3 \%) \\
3(20 \%) \\
1(6,7 \%) \\
9(60 \%)\end{array}$ & 0,744 \\
\hline $\begin{array}{l}\text { Sítio anatômico } \\
\text { Cardia } \\
\text { Corpo } \\
\text { Antro }\end{array}$ & 100 & $\begin{array}{l}3(37,5 \%) \\
1(12,5 \%) \\
4(50 \%)\end{array}$ & $\begin{array}{l}20(21,7 \%) \\
22(23,9 \%) \\
50(54,3 \%)\end{array}$ & 0,538 & 57 & $\begin{array}{c}0(0 \%) \\
2(66,7 \%) \\
1(33,3 \%)\end{array}$ & $\begin{array}{c}3(5,6 \%) \\
7(13 \%) \\
44(81,5 \%)\end{array}$ & 0,045 \\
\hline $\begin{array}{l}\text { Classificação } \\
\text { de Lauren } \\
\text { Intestinal } \\
\text { Difuso }\end{array}$ & 100 & $\begin{array}{l}7(87,5 \%) \\
1(12,5 \%)\end{array}$ & $\begin{array}{l}52(56,5 \%) \\
40(43,5 \%)\end{array}$ & 0,089 & 60 & $\begin{array}{l}3(100 \%) \\
0(0 \%)\end{array}$ & $\begin{array}{l}41(71,9 \%) \\
16(28,1 \%)\end{array}$ & 0,287 \\
\hline $\begin{array}{l}\text { pTNM } \\
\text { IA } \\
\text { IB } \\
\text { II } \\
\text { IIIA } \\
\text { IIIB } \\
\text { IV }\end{array}$ & 100 & $\begin{array}{c}0(0 \%) \\
1(12,5 \%) \\
1(12,5 \%) \\
1(12,5 \%) \\
2(25 \%) \\
3(37,5 \%)\end{array}$ & $\begin{array}{c}3(3,3 \%) \\
10(10,9 \%) \\
18(19,6 \%) \\
24(26,1 \%) \\
9(9,8 \%) \\
28(30,4 \%)\end{array}$ & 0,748 & 60 & $\begin{array}{c}0(0 \%) \\
0(0 \%) \\
0(0 \%) \\
1(33,3 \%) \\
2(66,7 \%) \\
0(0 \%)\end{array}$ & $\begin{array}{c}1(1,8 \%) \\
4(7 \%) \\
14(24,6 \%) \\
17(29,8 \%) \\
14(24,6 \%) \\
7(12,3 \%)\end{array}$ & 0,657 \\
\hline $\begin{array}{l}\text { Diferenciação } \\
\text { Indiferenciado } \\
\text { Pouco } \\
\text { Moderadamente } \\
\text { Bem diferenciado }\end{array}$ & 100 & $\begin{array}{c}0(0 \%) \\
2(25 \%) \\
6(75 \%) \\
0(0 \%)\end{array}$ & $\begin{array}{c}1(1,1 \%) \\
39(42,4 \%) \\
48(52,2 \%) \\
4(4,3 \%)\end{array}$ & 0,639 & 56 & $\begin{array}{c}0(0 \%) \\
1(50 \%)) \\
1(50 \%) \\
0(0 \%)\end{array}$ & $\begin{array}{c}0(0 \%) \\
19(35,2 \%) \\
22(40,7 \%) \\
13(24,1 \%)\end{array}$ & 0,726 \\
\hline
\end{tabular}

*Média geral de idade = 61,5; mediana = 63; mínimo = 23; máximo = 98; média de idade dos casos do Ceará = 61,2; média de idade dos casos de São Paulo =62,3; EBV: vírus Epstein-Barr; pTNM: TNM patológico.

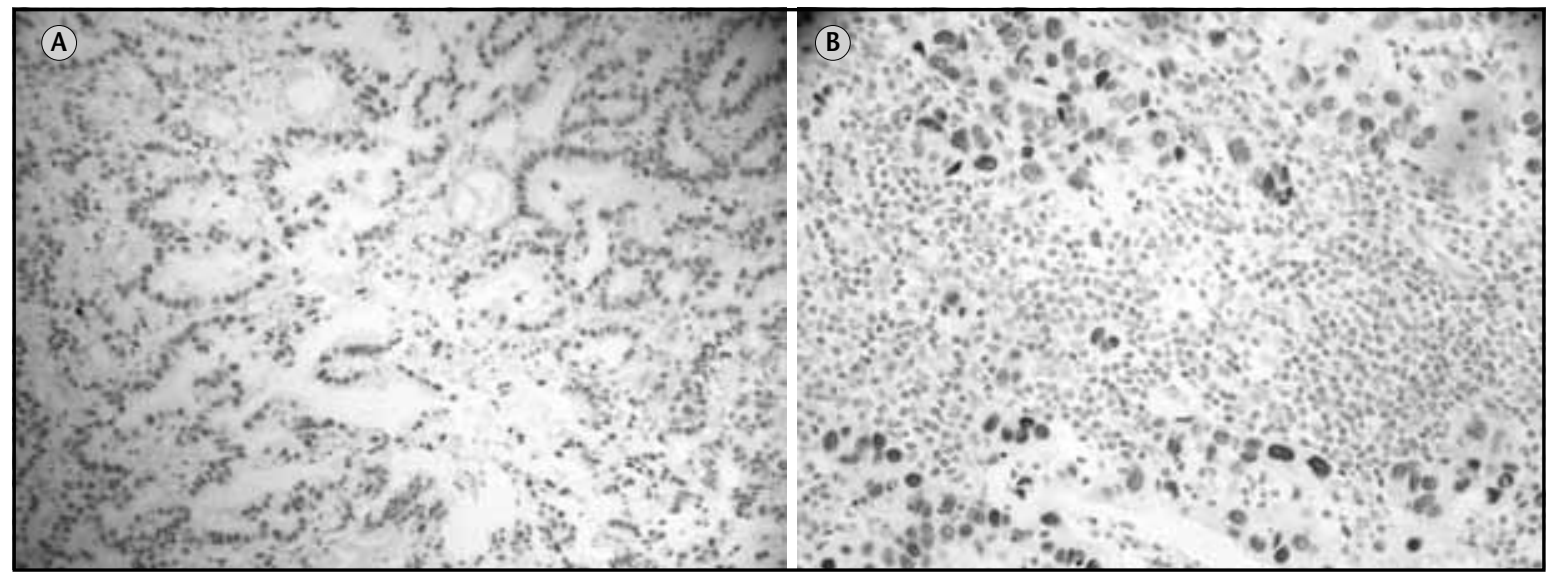

Figura - Presença de EBV em carcinoma gástrico detectada pela técnica de hibridização in situ. (A) Carcinoma do tipo intestinal de Lauren exibindo intensa marcação nuclear (400x); (B) carcinoma do tipo difuso de Lauren exibindo marcação nuclear intensa e difusa (600x).

EBV: vírus Epstein-Barr. 
em outros estudos, que a situação socioeconômica possa estar relacionada ${ }^{(2,8,37)}$, talvez pelas diferenças nos padrões alimentares e de conservação de alimentos, pela dificuldade de acesso à saúde ou ainda pela prevalência de Helicobacter pylori que, segundo Parkin et al. ${ }^{(36)}$, é mais elevada em adultos de países em desenvolvimento.

Neste estudo, os adenocarcinomas gástricos foram observados predominantemente em homens, sendo estes duas vezes mais acometidos que as mulheres, reproduzindo os achados da literatura mundial e do Brasil $\left.^{(2,} 6,8,10,11,24,37,44,45\right)$. Em indivíduos com idades avançadas, exibindo progressivo aumento após 40 anos de idade, alcançando os mais altos valores entre os sexagenários, esses resultados estão de acordo com a revisão feita por César et al.(6). Além disso, não foi verificado nenhum caso com idade inferior a 23 anos, reafirmando o caráter tardio dessa neoplasia.

Os casos de ambos os estados demonstraram uma predominância de tumores localizados no antro gástrico, reproduzindo achados de alguns autores $(39,43,44)$. Todavia, os pacientes de São Paulo apresentaram, em geral, quantidade menor de tumores situados na cárdia, em comparação com os do Ceará. A distribuição dos casos do Ceará quanto à localização anatômica dos tumores exibiu similaridades com dados obtidos em alguns países europeus, como Itália, Estônia e Suíça, e africano, como a Tunísia ${ }^{(44,45)}$. Os diferentes panoramas dos estados brasileiros em estudo estão, de certo modo, refletidos nos dados que mostraram significância estatística. Enquanto a maioria dos casos de São Paulo era do tipo intestinal, houve um equilíbrio nos casos do Ceará $(p=0,019)$. Não há um consenso sobre o tipo histológico entre os estudos de várias partes do mundo. Muitos autores

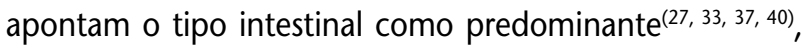
enquanto outros apontam o difuso ${ }^{(10,32,44)}$, mas nenhum tem relatado equivalência entre os dois tipos tumorais como observado nos casos procedentes do Ceará.

Realmente o tipo intestinal demonstra maior associação a indivíduos do sexo masculino e idosos, sendo confirmado no presente estudo ${ }^{(6,31,37,39)}$. Notou-se também, nos casos do Ceará, que o tipo difuso se sobrepõe ao intestinal nos grupos mais jovens (15-44 anos), corroborando César et al. ${ }^{(6)}$ e Shang e Peña ${ }^{(39)}$. Alguns autores relatam ainda relação dos tumores do tipo difuso com o sexo feminino ${ }^{(6,31)}$. Considerando o número reduzido de indivíduos do sexo feminino verificado neste estudo, o significativo percentual de carcinomas do tipo difuso acometendo mulheres (22/47 $[46,8 \%])$ indica que a relação mencionada também seja observada no grupo étnico aqui estudado.
Os resultados do TNM patológico (pTNM) denotaram o padrão agressivo dos tumores estudados, sobretudo daqueles do Ceará, demonstrando similaridades com trabalhos feitos na Inglaterra e nos Estados Unidos da América ${ }^{(2,10)}$ e em contraste com estudos realizados no Japão e na Coreia, os quais apresentaram números mais elevados de tumores com estadiamento I (cerca de $40 \%$ a $60 \%$ ), denotando o eficiente sistema de rastreamento de casos iniciais ${ }^{(2,20,23)}$. A correlação entre estadiamento tumoral e faixa etária demonstrou que os adultos jovens (15-44 anos) apresentaram neoplasias mais avançadas. Vale salientar que na correlação entre faixa etária e classificação de Lauren $(p=0,018), 66,7 \%$ dos casos pertencentes ao referido intervalo apresentaram adenocarcinomas do tipo difuso que, segundo a literatura, apresentam um decurso clínico mais agressivo, podendo ser a explicação para esse achado ${ }^{(47)}$.

Quanto à diferenciação tumoral, há uma escassez de dados na literatura mundial dificultando comparativos, entretanto parece que os tumores indiferenciados são incomuns. Neste estudo, os tumores pouco e moderadamente diferenciados foram mais frequentes. Além disso, nos casos de São Paulo foi verificada uma discreta elevação nos tumores bem diferenciados. Takano et al. ${ }^{(42)}$ e Lee et al. ${ }^{(23)}$ relataram uma predominância de tumores pouco diferenciados.

A frequência geral de EBV foi de 6,9\%, estando nos valores reportados pela literatura mundial que variam de $1,3 \%$ a $23,6 \%{ }^{(9,29)}$. O resultado observado nos casos do Ceará (8\%) demonstrou maior proximidade com as frequências de estudos realizados em países como Japão, China, Rússia, França, México, Malásia, Cazaquistão e Brasil, mais precisamente em São Paulo $(3,13,16,18,21,28,30,38,46,49)$; enquanto a frequência nos casos oriundos de São Paulo exibiu maior similaridade com trabalhos realizados em países como Itália, Japão, Coreia, Peru e Tunísia ${ }^{(1,7,23,25,32,44,48)}$. Sobre a marcação, notou-se positividade exclusivamente em células tumorais, não sendo constatada marcação em células pertencentes à mucosa normal ou lesões pré-neoplásicas, como metaplasia intestinal e displasia.

Entre os 11 casos positivos, nove demonstraram um padrão de marcação intenso e difuso, acometendo praticamente todas as células tumorais observáveis do tecido seccionado, enquanto os outros dois casos exibiram padrão focal de marcação. De acordo com Takada ${ }^{(41)}$, a presença do vírus na maioria das células tumorais, se não em todas, indica que o EBV exerce papel importante no desenvolvimento desses tumores. Porém, a presença do vírus em uma 
porção de células tumorais sugere que a infecção tenha ocorrido após a transformação neoplásica ${ }^{(28)}$.

A correlação entre a presença do EBV e o sexo dos indivíduos demonstrou um acometimento predominante do sexo masculino, concordando com os resultados da maioria dos estudos $(3,5,13,15,17,22,23,27,32,34,40,42,43,44,50)$. A respeito das faixas etárias, a média de idade dos casos EBV(+) demonstrou proximidade com os resultados obtidos por Takano et al. ${ }^{(42)}$, Oda et al. ${ }^{(32)}$, Lopes et al. ${ }^{(27)}$ e Trimeche et al. ${ }^{(44)}: 60,2 ; 59,4 ; 59$ e 55,7, respectivamente, que, em geral, denotam a predominância de tumores $\operatorname{EBV}(+)$ em idades mais avançadas.

Quanto à localização anatômica das neoplasias, entre os casos do Ceará, notou-se uma elevação percentual relativa dos tumores EBV(+) localizados na cárdia. Esse dado condiz com os achados de estudos realizados em diversas partes do mundo $(5,20,42,44,50)$. Alguns autores apontam a cárdia e o corpo como os sítios anatômicos mais associados à presença do EBV, não apresentando diferenças entre am$\operatorname{bos}^{(12,13,22,34,41,43,48)}$; outros indicam o antro gástrico ${ }^{(16,27)}$, mas não há relatos de predominância do EBV no corpo gástrico, como foi observado nos casos de São Paulo. Todavia, esse achado talvez possa ser decorrente do pequeno número de casos EBV(+) oriundos de São Paulo.

O envolvimento do EBV quanto ao tipo histológico de Lauren ainda é muito controverso. Alguns autores corroboram o predomínio, aqui observado, de carcinomas do tipo intestinal ${ }^{(15,49,50)}$. Entretanto, outros observaram predomínio de tumores do tipo difuso ${ }^{(3,21,22,32,43)}$ ou até mesmo uma equivalência entre ambos os tipos ${ }^{(5,40,41,44)}$. Ademais, Kijima et al. ${ }^{(20)}$ relatam que indivíduos com carcinomas do tipo intestinal $\mathrm{EBV}(+)$ apresentam piores prognósticos, quando em comparação com pacientes com carcinomas do tipo difuso, o que explicaria o predomínio observado de casos $\mathrm{EBV}(+)$ de estadiamentos avançados.

No que se refere ao estadiamento tumoral, observouse maior associação do EBV a tumores mais avançados, destacando-se o estadiamento IIIB, que apresentou significativo aumento em relação aos casos EBV(-). Por outro lado, alguns autores relatam que, em geral, os indivíduos que apresentam carcinomas $\mathrm{EBV}(+)$ demonstram melhor prognóstico ${ }^{(20,23)}$. Concordando com esses relatos e com os achados de Trimeche et al.(44), no presente estudo não foi verificada associação entre a presença do EBV e o desenvolvimento de metástases a distância. Assim, com base nos resultados apresentados e dados da literatura, é razoável supor que o referido vírus possa influenciar a progressão maligna, possivelmente por meio da desregulação de genes celulares envolvidos na proliferação celular e/ou apoptose, não devendo estar relacionado com alterações em genes envolvidos na adesão celular, mecanismo que favoreceria o desenvolvimento de metástases a distância.

Apesar de a associação do EBV ao grau de diferenciação apresentar-se nos graus mais comuns da amostra estudada, sua presença exclusiva nos tumores pouco e moderadamente diferenciados, sobretudo neste último, vai de encontro à literatura. A maioria dos estudos que avaliam esse critério histopatológico também observa o predomínio dos dois referidos graus de diferenciação ${ }^{(13,25,42,48)}$; apenas alguns apontam apenas o grau pouco diferenciado como preponderante ${ }^{(23,50)}$.

Apesar das diferenças de características clinicopatológicas e da associação com EBV entre os dois grupos estudados, ambos apresentaram similaridades com trabalhos realizados tanto em países desenvolvidos como em desenvolvimento, indicando que o fator socioeconômico não é determinante para essas disparidades, de modo que fatores ambientais, hábitos alimentares, origem étnica e raça podem ter correlação mais expressiva. Ademais, o genótipo viral também pode estar associado às diferenças observadas. Todavia, mais estudos ainda serão necessários para avaliar o papel desses fatores e elucidar as diferenças verificadas entre os grupos.

\section{Conclusão}

As diferenças clinicopatológicas observadas entre os casos procedentes de São Paulo e do Ceará refletem as diferenças socioeconômicas, ambientais e de hábitos dos dois grupos estudados. A frequência de tumores $E B V(+)$ deste estudo situa-se nos valores descritos na literatura mundial. Não obstante, o EBV predominou nos indivíduos do sexo masculino, de idades avançadas, em adenocarcinomas do tipo intestinal, de estadiamento avançado e de grau pouco a moderadamente diferenciado. Os casos procedentes de São Paulo exibiram maior proximidade com as frequências de estudos realizados na Itália, no Japão, na Coreia, na Tunísia e no Peru, enquanto os casos do Ceará com as de países como China, Rússia, França, México, Malásia, Cazaquistão e outros estudos realizados no Japão. Entre os achados, um deles não encontra paralelo na literatura mundial e refere-se ao elevado percentual de tumores EBV(+) no corpo gástrico observado nos casos de São Paulo. 


\section{Referências}

1. ABDIRAD, A. et al. Epstein-Barr virus associated gastric carcinoma: a report from Iran in the last four decades. Diagnostic Pathology, v. 2, n. 25, p. 1-9, 2007.

2. ALBERTS, S. R.; CERVANTES, A.; VAN DE VELDE, C. J. H. Gastric cancer: epidemiology, pathology and treatment. Annals of Oncology, v. 14, p. 31-6, 2003.

3. ALIPOV, G. et al. Epstein-Barr virus-associated gastric carcinoma in Kazakhstan. World J Gastroenterol, v. 11, n. 1, p. 27-30, 2005.

4. BRASIL. Ministério da Saúde. Instituto Nacional de Câncer. Coordenação de Prevenção e Vigilância. Estimativas 2010: incidência de câncer no Brasil. Rio de janeiro: INCA, 2009. Disponível em: < http://www.inca.gov.br> Acesso em: 22 out. 2010.

5. CARRASCAL, E. et al. Epstein-Barr virus associated gastric adenocarcinoma in Cali, Colombia. Oncol Rep, v. 10, n. 4, p. 1059-62, 2003.

6. CÉSAR, A. C. G.; SILVA, A. E.; TAJARA, E. H. Fatores genéticos e ambientais envolvidos na carcinogênese gástrica. Arq Gastroenterol, v. 39, n. 4, p. 253-9, 2002.

7. $\mathrm{CHO}, \mathrm{Y}$. J. et al. In situ hibridization of Epstein-Barr virus in tumor cells and tumor-infiltrating lymphocytes of the gastrointestinal tract. Human Pathology, v. 32, n. 3, p. 297-301, 2001.

8. CIPRIANI, F.; BUIATTI, E.; PALLI, D. Gastric cancer in Italy. Ital J Gastroenterol, v. 23, n. 7, p. 429-35, 1991.

9. CORVALAN, A. et al. Clinical and molecular features of cardiac gastric cancer associated to Epstein Barr virus. Rev Med Chil, v. 133, n. 7, p. 753-60, 2005.

10. CUNNINGHAM, S. C. et al. Survival after gastric adenocarcinoma resection: eighteen-year experience at a single institution. Gastointestinal Surgery, v. 9, n. 5, p. 718-25, 2005.

11. DE STEFANI, E. et al. Alcohol drinking and tobacco smoking in gastric cancer. A case-control study. Rev Epidemiol Sante Publique, v. 38, n. 4, p. 297-307, 1990.

12. FUKAYAMA, M. et al. Epstein-Barr virus-associated gastric carcinoma and Epstein-Barr virus infection of the stomach. Lab Invest, v. 71, n. 1, p. 73-81, 1994.

13. GALETSKY, S. A. etal. Epstein-Barr-virus associated-gastric cancer in Russia. Int J Cancer, v. 73, p. 786-9, 1997.

14. GULLEY, M. L. et al. Epstein-Barr virus infection is an early event in gastric carcinogenesis and is independent of bcl-2 expression and p53 accumulation. Hum Pathol, v. 27 , n. 1, p. 20-7, 1996.

15. HARN, H. J. et al. Epstein-Barr virus-associated gastric adenocarcinoma in Taiwan. Hum Pathol, v. 26, n. 3, p. 267-71, 1995.

16. HERRERA-GOEPFERT, R. et al. Epstein-Barr-virus associated gastric carcinoma in Mexico: analysis of 135 consecutive gastrectomies in two hospitals. Mod Pathol, v. 12, p. 873-8, 1999.

17. ISHII, H. et al. Interrelationship between Epstein-Barr virus infection in gastric carcinomas and the expression of apoptosis-associated proteins. Histopathology, v. 38, p. 111-9, 2001.
18. KARIM, N.; PALLESEN, G. Epstein-Barr virus (EBV) and gastric carcinoma in Malaysian. Malays J Pathol, v. 25, n. 1, p. 45-7, 2003.

19. KIEFF, E. Epstein-Barr virus and its replication. In: FIELDS, B. N.; KNIPE, D. M.; HOWLEY, P. M. et al. Fundamental virology. 3. ed. Philadelphia: Lippincott-Raven, 1996. p. 1109-63.

20. KIJIMA, Y. et al. The comparison of prognosis between Epstein-barr virus (EBV)-positive gastric carcinomas and EBV-negative ones. Cancer Letters, v. 200, p. 33-40, 2003.

21. KORIYAMA, C. et al. Epstein-Barr virus-associated gastric carcinoma in Japanese Brazilians and Non-Japanese Brazilians in São Paulo. Jpn J Cancer Res, v. 92, p. 911-7, 2001.

22. KORIYAMA, C. et al. Histology-specific gender, age and tumor-location distributions of Epstein-Barr virusassociated gastric carcinoma in Japan. Oncol Rep, v. 12, n. 3, p. 543-7, 2004.

23. LEE, H. S. et al. Epstein-Barr virus-positive gastric carcinoma has a distinct protein expression profile in comparison with Epstein-Barr virus-negative carcinoma. Clinical Cancer Research, v. 10, p. 1698-705, 2004.

24. LEMES, L. A. O. et al. Carcinoma gástrico: análise sistemática de 289 gastrectomias consecutivas em Belo Horizonte (MG). JBPML, v. 39, n. 1, p. 57-65, 2003.

25. LEONCINI, L. et al. Epstein-Barr virus and gastric cancer: data and unanswered questions. Int J Cancer, v. 53, n. 6, p. 898-901, 1993.

26. LIMA, M. A. P.; RABERHORST, S. H. B. Associação do vírus de Epstein-Barr (EBV) com tumores sólidos. Revista Brasileira de Cancerologia, v. 52, n. 1, p. 87-96, 2006.

27. LOPES, L. F. et al. Epstein-Barr virus infection and gastric carcinoma in São Paulo state, Brazil. Brazilian Journal of Medical and Biological Research, v. 37, n. 11, p. 1707-12, 2004.

28. LUO, B. et al. Expression of Epstein-Barr virus genes in EBV-associated gastric carcinomas. World J Gastroenterol, v. 11, n. 5, p. 629-33, 2005.

29. MOREWAYA, J. et al. Epstein-Barr virus-associated gastric carcinoma in Papua New Guinea. Oncol Rep, v. 12, n. 5, p. 1093-8, 2004.

30. NAKAMURA, S. et al. Epstein-Barr virus in gastric carcinoma with lymphoid stroma. Special reference to its detection by the polymerase chain reaction and in situ hybridization in 99 tumors, including a morphologic analysis. Cancer, v. 73, n. 9, p. 2239-49, 1994.

31. NARDONE, G. Review article: molecular basis of gastric carcinogenesis. Aliment Pharmacol Ther, v. 17, p. 75-81, 2003.

32. ODA, K. et al. Detection of Epstein-Barr virus in gastric carcinoma cells and surrouding lymphocytes. Gastric Cancer, v. 6, p. 173-8, 2003.

33. OLUWASOLA, A. O.; OGUNBIVI, J. O. Gastric cancer: aetilogical, clinicopathological and management patterns in Nigeria. Niger J Med, v. 12, n. 4, p. 177-86, 2003. 
34. OSATO, T.; IMAI, S. Epstein-Barr virus and gastric carcinoma. Seminars in Cancer Biology, v. 7, p. 175-82, 1996.

35. OTT, G.; KIRCHNER, T.; MULLER-HERMELINK, H. K. Monoclonal Epstein-Barr virus genomes but lack of EBV-related protein expression in different types of gastric carcinoma. Histopathology, v. 25, n. 4, p. 323-9, 1994.

36. PARKIN, D. M. et al. Global cancer statistics, 2002. CA Cancer J Clin, v. 55, p. 74-108, 2005.

37. RODER, D. M. The epidemiology of gastric cancer. Gastric Cancer, v. 5, p. 5-11, 2002.

38. SELVES, J. et al. Epstein-Barr virus latent and replicative gene expression in gastric carcinoma. Histopathology, v. 28, n. 2, p. 121-7, 1996.

39. SHANG, J.; PEÑA, A. S. Multidisciplinary approach to understand the pathogenesis of gastric cancer. World J Gastroenterol, v. 11, n. 27, p. 4131-9, 2005.

40. SHIBATA, D.; WEISS, L. M. Epstein-Barr virus-associated gastric adenocarcinoma. Am J Pathol, v. 140, p. 769-74, 1992.

41. TAKADA, K. Epstein-Barr virus and gastric carcinoma. J Clin Pathol: Mol Pathol, v. 53, p. 255-61, 2000.

42. TAKANO, Y. et al. The role of the Epstein-barr virus in the oncogenesis of $\mathrm{EBV}(+)$ gastric carcinomas. Virchows Achieves, v. 434, p. 17-22, 1999.
43. TOKUNAGA, M. et al. Epstein-Barr virus related gastric cancer in Japan: a molecular patho-epidemiological study. Acta Pathologica Japonica, v. 43, p. 574-81, 1993.

44. TRIMECHE, M. et al. Prevalence and characteristics of Epstein-Barr virus-associated gastric carcinomas in Tunisia. European Journal of Gastroenterology \& Hepatology, v. 21, p. 1001-7, 2009.

45. VERDECCHIA, A. et al. Explaining gastric cancer survival differences among European countries. Int J Cancer, v. 109, p. 737-41, 2004.

46. WANG, Y. et al. Expression of Epstein-Barr virus genes in EBV-associated gastric carcinoma. Ai Zheng, v. 23, n. 7, p. 782-7, 2004.

47. WERNER, M. et al. Gastric adenocarcinoma: pathomorphology and molecular pathology. J Cancer Res Clin Oncol, v. 127, p. 207-16, 2001.

48. YOSHIWARA, E. et al. Epstein-Barr virus-associated gastric carcinoma in Lima, Peru. J Exp Clin Cancer Res, v. 24, n. 1, p. 49-54, 2005.

49. YUEN, S. T. et al. In situ detection of Epstein-Barr virus in gastric and colorectal adenocarcinomas. Am J Surg Pathol, v. 18, n. 11, p. 1158-63, 1994.

50. ZUR HAUSEN, A. et al. Epstein-Barr virus in gastric carcinomas and gastric stump carcinomas: a late event in gastric carcinogenesis. J Clin Pathol, v. 57, p. 487-91, 2004. 